\title{
PEMANFAATAN MEDIA PETA DALAM PEMBELAJARAN IPS KELAS V DI MI AL-MUNIROH 1 UJUNG PANGKAH
}

\author{
I Rasiman', Taseman², I Kartikasari ${ }^{3}$, M W Laili4, Muzdalifa'5, S Maryam ${ }^{6}$ \\ 1, 2 Institute University of Islamic Al Khoziny Sidoarjo, Indonesia \\ 3, 4, 5, 6 Islamic State University of Sunan Ampel, Surabaya, Indonesia
}

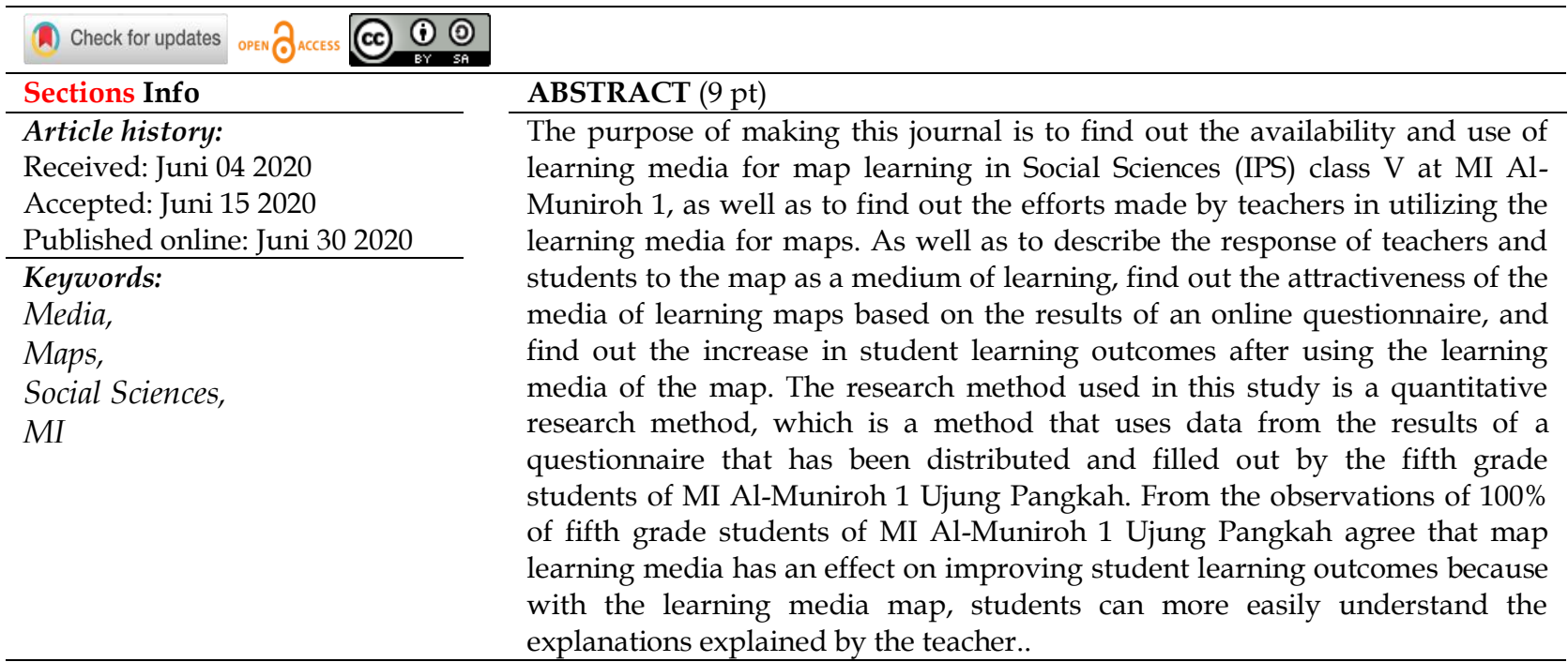

\section{INTRODUCTION}

Pendidikan merupakan suatu hal yang tidak bisa dipisahkan dengan kehidupan manusia. Setiap individu tanpa terkecuali berhak mendapatkan pendidikan. Hal ini tercantum dalam pasal 31 Undang-Undang Dasar 1945 (amandemen) yang berbunyi "Setiap warga Negara berhak mendapatkan pendidikan". Dengan demikian, pendidikan merupakan salah satu hak asasi manusia yang wajib dipenuhi. Menurut Yuswanti (2013: 185) "Pendidikan seperti sifatnya yaitu manusia, mengandung banyak aspek dan sifatnya sangat kompleks". Pendidikan merupakan suatu hal yang sangat mutlak dan penting untuk dipenuhi dalam usaha untuk meningkatkan taraf hidup Bangsa Indonesia agar bisa setara dengan Negara lain dalam menyiapkan SDM nya yang berkualitas dan berdaya saing (Ismail, 2015).

Makna pendidikan dapat diartikan sebaga upaya manusia untuk membetuk pribadi agar memiliki karakter, sikap yang sesuai dengan nilai-nilai serta norma-norma yang telah ditetapkan di dalam masyarakat. Salah satu indikator pendidikan yang berkualitas adalah perolehan nilai hasil belajar siswa setiap harinya serta pemahaman materi yag bisa ditangkap siswa. Untuk dapat memaksimalkan pembelajaran dalam menyampaikan materi dibutukanlah media peta pembelajaran untuk lebih mempermuda pemahaman siswa agar muda dalam memahami materi tempat atau kewilayahan tertentu terkait pelajaran IPS (Gani, 2019).

Pendidikan berkualitas dalam proses pembelajarannya pasti memperhatikan unsur yang mendukung diantaranya media sebagai sarana penyampai materi yang tidak bisa terlepas dari strategi, metode, teknik, dan media pembelajaran. Kualitas 
pembelajaran menjadi ujung tombak dalam keberhasilan belajar manakalah media yang digunakan menyampikan materi mata pelajaran IPS sesuai dengan maksud dan tujuan pembelajaran (Sari, 2018), (Ardiansyah, 2015).

Letak keberhasilan pembelajaran bisa didukung media yang tepat dan sesuai, sebagaimana ada peningkatan hasil belajar yang signifikan dengan menggunakan media peta pada bahasan mengenal peta (Haerunnisa, 2019). Dukungan keberhasilan belajar juga bisa berasal dari pendidik (guru) teacher canter yang memiliki kewajiban dalam mentranfer ilmunya dan tugas serta kewajibannya, guru harus menentukan media yang tepat guna dan sesuai dengan media pembelajaran yang digunakan.

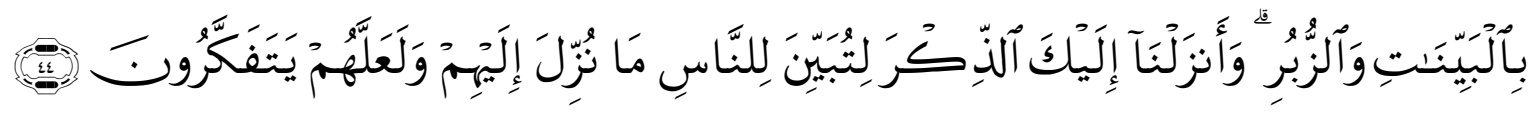

Artinya: (44). keterangan-keterangan (mukjizat) dan kitab-kitab. dan Kami turunkan kepadamu Al Quran, agar kamu menerangkan pada umat manusia apa yang telah diturunkan kepada mereka [829] dan supaya mereka memikirkan, [829] Yakni: perintah-perintah, larangan-larangan, aturan dan lain-lain yang terdapat dalam Al Quran.

Menurut Ramli (2015:133) masalah penerapan media pembelajaran, guru harus memperhatikan dengan benar perkembangan jiwa religius anak didik, karena faktor inilah yang justru menjadi sasaran media pembelajaran. Tanpa memperhatikan serta memahami perkembangan jiwa anak atau tingkat daya pikir anak didik, guru akan sulit diharapkan untuk dapat mencapai keberhasilan. Ali Muhson (2010:2) mengutip pendapat dari Association for Education and Communication of Technology (AECT) yang mengatakan bahwa media merupakan segala bentuk yang dipergunakan untuk menyalurkan informasi. Sedangkan National Education Association (NEA) berpendapat bahwa media merupakan suatu benda yang digunakan dalam kegiatan belajar mengajar dan dapat memengaruhi efektifitas program instruksional yang mana benda tersebut dapat dimanipulasi, dilihat, didengar, dibaca atau dibicarakan beserta instrumen yang dipergunakan dengan baik. Muhibuddin Fadhli (2015:24) mengatakan bahwa terdapat beberapa pendapat para ilmuwan tentang media pembelajaran, salah satunya ialah Briggs yang berpendapat bahwa media merupakan alat untuk memberikan rangsangan atau stimulus pada siswa agar terjadi proses belajar (Hendra Septian Dalimunthe, Sri Utami, 2015).

Media pembelajaran merupakan faktor penunjang keberhasilan proses pembelajaran, adanya media pembelajaran menjadikan siswa mudah memahami materi, bahkan termotivasi untuk semangat belajar, karena media pembelajaran dapat menarik perhatian siswa untuk terlibat aktif saat belajar serta menjadikan pembelajaran lebih bermakna (Maharani, 2015). Adanya ketersediaan media pembelajaran ketika proses pembelajaran dikelas sangatlah penting. Adapun metode yang digunakan pada masa Muhammad SAW diantara salah satunya adalah dialog dan diskusi (al-hiwar wa al-mujadalah), Metode pendidikan seperti itu membuat guru dan anak didik menjadi aktif, kalau dipahami kembali ke zaman Nabi Muhammad SAW sebenarnya media pembelajaran sudah tersedia dan digunakan beliau dalam menyampaikan ilmu pengetahuan kepada sahabat-sahabatnya tidak terlepas dari adanya media sebagai sarana penyampaian materi (Pito, 2018), (Ramli, 2015), (Abidin, 2003). 
Dalam proses pembelajaran IPS, media pembelajaran sangat penting digunakan, karena di dalam pembelajaran IPS terdapat materi tentang pesan-pesan abstrak, arah mata angin, kebudayaan Indonesia, lingkungan, kenampakan alam, pembagian waktu dan lainnya. Oleh karena itu, guru perlu membuat media pembelajaran seperti peta, gambar, grafik, miniatur untuk memahamkan konsep yang abstrak kepada siswa sehingga siswa lebih mudah dalam memahami materi. Menurut Hamidullah (2019:36) media pembelajaran dapat lebih menarik perhatian siswa sehingga bisa menumbuhkan motivasi belajar (Taseman, I Rasiman, dkk, 2020).

Menurut Irsyad Azhar (2010:10), dari segi kemampuan, pembuatan, dan cara penggunaannya media mempunyai karakteristik tertentu. Setiap media memiliki karakteristik tersendiri dilihat dari beberapa segi, misalkan dari segi ekonomisnya, karakter media menurut Schramm adalah mudahnya penggunaan media oleh pemakainya. Mukminan (2010: 13) mengklafisikan media pembelajaran menjadi lima jenis, pertama, media visual yang tidak diproyeksikan seperti gambar diam, bahanbahan grafis, model dan realita. Kedua, media visual yang diproyeksikan seperti OHP, slide (film bingkai), film strip (film rangkai). Ketiga, media audio seperti sound system. Keempat, sitem multimedia seperti menggunakan komputer untuk menampilkan program power point, atau CD yang digunakan untuk pembelajaran. Kelima, Permainan dan simulasi. Menurut Asma Sari (2015:28) peta atau map adalah gambar seluruh sebagian dari permukaan bumi yang dilukiskan ke suatu bidang datar dengan perbandingan atau skala tertentu. Pada KBBI peta adalah suatu gambaran atau lukisan pada kertas dan lainnya yang menunjukkan letak tanah, laut, sungai, gunung dan sebagainya (Taseman, 2020).

Kajian penelitian menggunakan data kuesioner/angket online yang telah diisi oleh para siswa kelas V MI Al-Muniroh 1 agar peneliti dapat mengambil data konkret mengenai ketersediaan media pembelajaran peta dan manfaat media peta tersebut dalam membentuk pemahaman siswa pada saat proses pembelajaran serta ketercapaiannya tujuan dari pembelajaran tersebut. Tujuan penelitian ini adalah untuk mengetahui apakah media pembelajaran peta berpengaruh terhadap siswa untuk lebih meningkatkan pemahaman materi yang disampaikan oleh guru. Berdasarkan permasalahannya dapat dirumuskan: 1). Bagaimana respon para siswa kelas V MI AlMuniroh 1 Ujung Pangkah ketika guru menggunakan media peta dalam proses pembelajaran?, 2). Seberapa efektivitaskah media pembelajaran peta terhadap pemahaman para siswa kelas V MI Al-Muniroh 1 Ujung Pangkah pada saat guru menggunakannya dalam proses pembelajaran?, 3). Bagaimana peningkatan hasil belajar para siswa kelas V MI Al-Muniroh 1 Ujung Pangkah setelah guru menggunakan media peta dalam proses pembelajaran?, 4). Apakah tujuan pembelajaran lebih mudah tercapai ketika guru menggunakan sebuah media pembelajaran pada saat proses belajar mengajar berlangsung?.

\section{RESEARCH METHOD}

Adapun metode penelitian yang digunakan yaitu metode penelitian kuantitatif (quantitative research). A. Muri Yusuf (2014: 46) berpendapat bahwa metode penelitian 


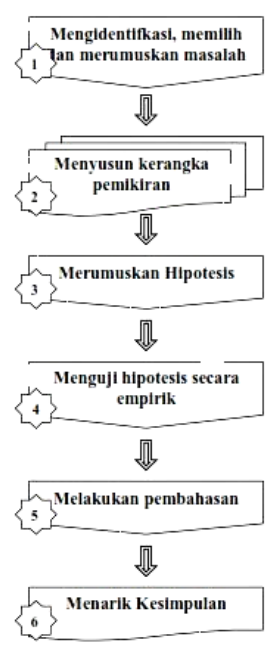

kuantitatif merupakan metode yang menguji sebuah teori yang sejak awal sudah ditentukan dan direncanakan secara rinci, jelas dan teratur, baik itu objek/sampel penelitiannya, langkah-langkah penelitiannya, instrumen penelitiannya, teknik pengumpulan datanya, hingga tujuan penelitiannya. Dalam metode penelitian kuantitatif tersebut memilih teknik pengumpulan data menggunakan kuesioner dengan instrumen angket online yang telah dibuat melalui google form dan memilih para siswa kelas V MI Al-Muniroh 1 Ujung Pangkah sebagai sampel penelitian kami. Metode penelitian yang kami lakukan adalah metode penelitian kuantitatif, sehingga kami pun melakukan prosedur penelitian sesuai dengan langkah-langkah yang terdapat dalam metode kuantitatif tersebut.

Pertama, mengidentifikasi dan merumuskan masalah. Selanjutnya mengidentifikasi lembaga pendidikan MI Al-Muniroh 1 Ujung Pangkah yang akan kami gunakan sebagai objek penggalian data, peneliti memilih MI Al-Muniroh 1 Ujung Pangkah karena letak dekat, serta kesempatan yang telah diberikan. adapun tema yang diambil yaitu kebermanfaatan sebuah media pembelajaran peta terhadap tingkat pemahaman para siswa sekaligus tercapainya tujuan dari pembelajaran, inti rumusan masalah: 1) Apakah terdapat pengaruh antara ada dan tidaknya sebuah media pembelajaran peta bagi siswa dalam memahami materi (peta) yang diajarkan oleh guru?, 2) Apakah tujuan pembelajaran yang dirancang oleh guru dapat lebih mudah tercapai dengan adanya media pembelajaran peta tersebut?. Kedua, menyusun kerangka pemikiran. Kami berdiskusi menentukan satu instrumen penelitian, yakni kuesioner berupa angket online yang berisi rumusan-rumusan masalah. Ketiga, kami merumuskan hipotesis. Melalui angket yang telah dibuat kemudian disebar unuk siswa kemudian disuruh mengisi angket yang telah disediakan. Kami menemukan hipotesa bahwa sebuah media pembelajaran peta dapat mempengaruhi tingkat pemahaman siswa, sehingga siswa dapat lebih mudah memahami materi (tentang peta) apabila guru menjelaskan materi menggunakan media nyatanya (peta) tersebut yang dapat mengembangkan imajinasi siswa terhadap letak suatu daerah dan dengan pemahaman materi yang matang tersebutlah tujuan pembelajaran yang telah dibuat oleh guru dapat lebih mudah tercapai.

Empat, menguji hipotesis secara empiris dengan mengumpulkan data melalui angket kuesioner yang berisi mengenai pertanyaan yang menjadi rumusan-rumusan masalah yang mana angket tersebut sebarkan melalui via online/handphone agar siswa dapat dengan lebih mudah mengisi dan kami pun lebih mudah dalam menentukan presentase jawaban dari setiap rumusan masalah. Lima, melakukan pembahasan. Setelah kami mendapat sampel dari para siswa kelas V MI Al-Muniroh 1 Ujung Pangkah melalui angket online, kami melakukan pembahasan atau diskusi kelompok dalam menentukan hasil penelitian. Enam, menarik kesimpulan. Kami menarik kesimpulan bahwa para siswa kelas V MI Al-Muniroh 1 Ujung Pangkah merasa 
terbantu dan lebih mudah memahami materi peta apabila guru menjelaskannya (materi peta) dengan membawa media pembelajaran realnya, yakni peta.

Pelaksanaan metode penelitian kuantitatif ini menggunakan teknik pengumpulan data berupa kuesioner yang mana kuesioner tersebut berupa angket yang didalamnya terdapat rumusan-rumusan masalah yang akan dijawab oleh para siswa. Kuesioner tersebut buat melalui aplikasi google form yang mana link dari kuesioner tersebut dapat dengan mudah kami kirim kepada para siswa dan dengan mudah pula kami mengumpulkan data penelitiannya berupa statistik data. Instrumen pengumpulan data yang kami gunakan adalah sebuah angket online. Dengan berkembangnya zaman sekaligus kondisi saat ini (wabah pandemi), kami rasa dengan adanya angket online tersebut dapat memudahkan kami melakukan penelitian dengan menggunakan metode kuantitatif yang mana hasil dari metode tersebut merupakan statistik data.

\section{RESULTS AND DISCUSSION}

Hasil paparan penelitian, pertama peneliti menyusun dan mempersiapkan instrumen pengumpul data berupa angket online yang bisa diisi oleh siswa. Angket kuesioner online digunakan untuk mengetahui ketersediaan media pembelajaran yang sedang yaitu 1) Apakah terdapat pengaruh antara ada dan tidaknya sebuah media pembelajaran peta bagi siswa dalam memahami materi (peta) yang diajarkan oleh guru, 2) Apakah tujuan pembelajaran yang dirancang oleh guru dapat lebih mudah tercapai dengan adanya media peta tersebut. Setelah menyusun dan mempersiapkan instrumen pengumpul data, kemudiaan peneliti melaksanakan penelitian dengan menyebarkan angket secara online pada siswa kelas V MI Al-Muniroh 1 Ujung Pangkah pada tanggal 30 April 2020 sampai 2 Mei 2020. selanjutnya sesudah angket dishare secara online, siswa-siswi dimintak untuk mengisi dan menjawab angket secara online (daring), selama (Pandemi Covid-19) sehingga tidak memugkinkan peneliti mengambil data secara langsung di MI Al-Muniroh 1 Ujung Pangkah karena saat ini siswa MI AlMuniroh melaksanakan aktivitas belajar di rumah secara daring (online).

Dari hasil observasi dan pengolahan data siswa kelas V di MI Al-Muniroh 1 Ujung Pangkah diperoleh hasil bahwa 100\% siswa mengeatahui tentang peta mulai dari pengertian peta, unsur-unsur peta, serta simbol-simbol yang terdapat pada peta. Tetapi untuk jenis-jenis peta, presentase pemahaman siswa yang kami dapatkan sebagai berikut: $0 \%$ siswa yang mengetahui tentang Peta Kota/Kabupaten, $70 \%$ siswa mengetahui tentang Peta Provinsi, 14,3\% siswa yang mengetahui tentang Peta Indonesia, 0\% siswa yang mengetahui tentang Peta Benua, dan 14,3\% siswa yang mengetahui tentang Peta Dunia. Sedangkan presentase pengaruh pemanfaat media peta terhadap kemudahan para siswa dalam memahami materi yang disampaikan oleh guru adalah $100 \%$. Dan dari angket kuesioner tersebut pula dapat kami ketahui bahwa $100 \%$ siswa pernah menggambar peta. Dari uraikan di atas dapat disimpulkan bahwa media pembelajaran peta sangat bermanfaat untuk meningkatkan pemahaman siswa. 


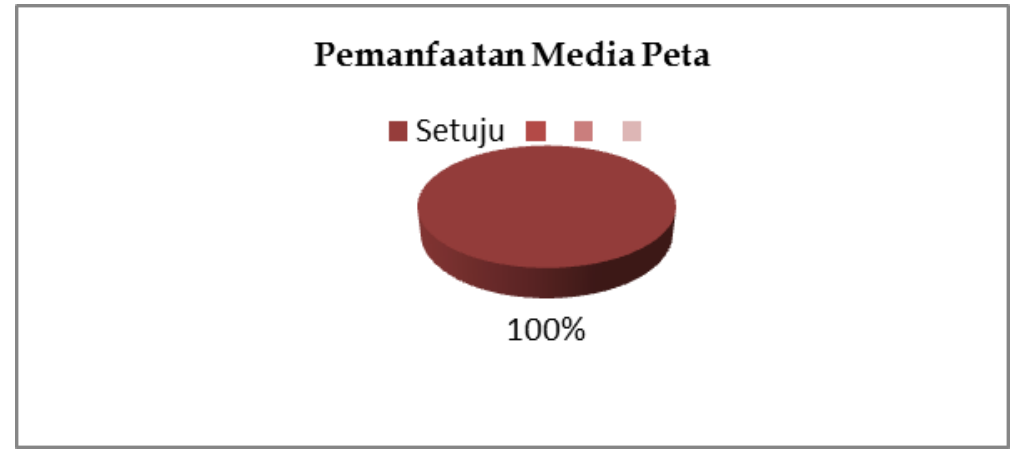

Gambar 1. Penggunaan Media Peta Dalam Pembelajaran IPS

Berdasarkan hasil penelitian yang telah lakukan, bahwa menggunakan media pembelajaran peta dapat memberikan pengaruh untuk meningkatkan hasil belajar siswa karena dengan adanya media peta siswa lebih mudah memahami materi yang dijelaskan oleh guru, untuk lebih mengetahui letak suatu wilayah, tempat, ketinggian dan dataran topografi daerah tertentu, siswa lebih tertarik saat menggunakan media peta dalam pembejaran IPS karena adanya pemahaman langsung terhadap objek kenampakan dari pencitraan alam. Adapaun masukan sebaiknya jika guru menggunakan media pembelajaran berupa peta, peta yang digunakan oleh guru berukuran besar yang bisa ditempelkan di papan tulis sehingga dapat dilihat oleh semua siswa.

Guru menggunakan media dalam proses pembelajaran jika sudah terdapat media agar sesuai dengan materi pembelajaran yang akan diajarkan agar lebih maksimal dan fokus sesuai bahasan. Kemudian berkaitan dengan pemanfaatan media yang dilakukan oleh guru dalam pembelajaran IPS yaitu media pembelajaran sangat membantu dalam proses pembelajaran dan membantu siswa memahami materi, untuk bisa memberikan kemudahan untuk guru dalam menjelaskan materi dan proses pembelajaran berjalan dengan baik sesuai dengan tujuan pembelajaran.

Kesulitan yang sering ditemukan guru dalam memanfaatkan media pembelajaran IPS adalah guru susah menggunakan media jika kondisi kelas ramai ketika guru menjelaskan materi menggunakan media, masih ada media susah mencari media pembelajaran yang sesuai dengan materi yang susuah, guru belum bisa menggunakan media dengan baik dan ketika ada siswa yang tidak mengerti tentang isi materi, meskipun telah dibantu dengan media. Selanjutnya yang paling mempengaruhi guru dalam memanfaatkan media pembelajaran IPS adalah ketersediaan media di sekolah, pengetahuan guru tentang media dan keikutsertaan siswa dalam proses pembelajaran.

\section{CONCLUSIONS}

Conclusions, Berdasarkan hasil penelitian dan pembahasan yang telah dijelaskan diatas, media pembelajaran sangat bermanfaat dalam proses pembelajaran karena dapat membantu siswa lebih mudah memahami materi, memotivasi siswa untuk lebih semangat dalam belajar. Guru juga lebih mudah menjelaskan materi jika menggunakan media pembelajaran, dan pesan yang disampaikan guru mudah ditangkap, juga dipahami oleh siswa, serta tujuan pembelajaran dapat lebih mudah tercapai. Setiap 
media pembelajaran memiliki karakteristik tersendiri baik dari segi pembuatan media, penggunaan media maupun fungsi media. Banyak sekali manfaat dari adanya media pembelajaran yang juga berpengaruh pada hasil nilai belajar siswa.

Dengan diketahuinya bahwa media pembelajaran sangat penting terhadap pengaruh bagi siswa maupun tujuan pembelajaran, maka saran kami sebagai penulis adalah (terkhusus bagi para pendidik) berusahalah untuk membuat atau menyediakan media pembelajaran yang sesuai dengan materi ajar sekalipun media tersebut sederhana tetapi harus memuat atau mengandung poin-poin penting materi pembelajaran tersebut, karena dengan adanya media pembelajaran dapat lebih membantu para siswa dalam memahami sekaligus mematangkan pemahaman yang telah dijelaskan atau diajarkan oleh guru.

\section{ACKNOWLEDGEMENTS (OPTIONAL)}

Peneliti mengucapkan terima kasih kepada IAI Al Khoziny Sidoarjo dan PGMI FTK UINSA Surabaya atas dukungan dan bantuan dalam hasil penelitian ini.

\section{REFERENCES}

Abidin, Z. (2003). WAWASAN HADIS TENTANG ALAT DAN MEDIA PENDIDIKAN. J u r $n$ a $l$ ANSIRU PA, 2(2), 107-119. https://doi.org/10.16309/j.cnki.issn.10071776.2003.03.004

Ardiansyah, Y. (2015). Pengaruh Penggunaan Media Sistem Informasi Geografi (SIG) Pada Pembelajaran IPS Pokok Bahasan Peta Terhadap Peningkatan Hasil Belajar. Laporan Akhir Skripsi, 01(01), 1-17. https:/ / doi.org/10.1017/CBO9781107415324.004 Azhar, Irsyad. (2010). Media Pembelajaran. Jakarta : PT Raja Grafindo Persada.

Fadhli, Muhibuddin. (2015). Pengembangan Media Pembelajaran Berbasis Video Kelas IV Sekolah Dasar. Jurnal Dimensi Pendidikan dan Pembelajaran. 3 (1) : 24

Gani, A. A. (2019). Interaksi Antara Pemanfaatan Media Pembelajaran Dan Gaya Belajar Terhadap Hasil Belajar Ips Terpadu. CIVICUS: Pendidikan-Penelitian-Pengabdian $\begin{array}{lllll}\text { Pendidikan Pancasila Dan } & 82 .\end{array}$ https://doi.org/10.31764/civicus.v6i2.677

Haerunnisa. (2019). Pemanfaatan Media Peta Untuk Meningkatkan Motivasi dan Hasil Belajar Siswa Pada Mata Pelajaran IPS Dengan Pokok Bahasan Mengenal Peta Provinsi (PTK Pada Siswa Kelas IV MIS Al-Husna Kota Tangerang). Laporan Akhir Skripsi, 01(01), 1-224. https:// doi.org/10.1017/CBO9781107415324.004

Hendra Septian Dalimunthe, Sri Utami, S. M. (2015). Ketersediaan dan Pemanfaatan Media Non Proyeksi IPS Kelas V SDN Kecamatan Pontianak Tenggara. Jurnal Pendidikan Islam, 01(01), 1-12.

Ismail, S. N. (2015). Pemanfaatan Peta Tematik Sebagai Media Pembelajaran Mata Pelajaran Sejarah Untuk Meningkatkan Aktifitas Dan Hasil Belajar Peserta Didik Kelas XI IPS MA Raudlotul Huffadz Kediri Tabanan Tahun Pelajaran 2014/2015. Laporan Akhir Skripsi, 1(May), 1-9. https:/ / doi.org/10.1017/CBO9781107415324.004 Ibda, Hamidullah. (2019). Media Pembelajaran Berbasis Wayang. Semarang: CV Pilar Nusantara 
Maharani, W. (2015). Peningkatan Spatial Literacy Siswa Sekolah Dasar Melalui Pemanfaatan Media Peta Dalam Pembelajaran IPS (Studi Eksperimen Kuasi Siswa Kelas IV SD Laboratorium Percontohan UPI. Jurnal Pendidikan, 01(01), 1-2.

M. Ramli. (2015). Media Pembelajaran dalam Perspektif Al-Quran dan Al-Hadis. Ittihad Jurnal Kopertais Wilayah XI Kalimantan. 13 (23) : 133-135

Muhson, Ali. (2010). Pengembangan Media Pembelajaran Berbasis Teknologi Informasi. Jurnal Pendidikan Akuntansi Indonesia. 8 (2) : 2-3

Mukminan. (2010). Teknologi Informasi Dan Media Pembelajaran Ilmu Pengetahuan Sosial.

Pito, A. H. (2018). Media Pembelajaran dalam Perspektif Al-Qur'an. Andragogi: Jurnal Diklat Teknis Pendidikan Dan Keagamaan, 6(2), 97-117. https:// doi.org/10.36052/andragogi.v6i2.59

Ramli, M. (2015). Media Pembelajaran Dalam Perspektif. Jurnal Kopertais Wilayah XI Kalimantan Volume, 13(23), 130-154.

Sari, E. N. (2018). Analisis Ketersediaan dan Pemanfaatan Media Pembelajaran Geografi Pada Materi Biosfer Kelas XI IPS SMA di Kecamatan Berastagi Tahun Pelajaran 2017 /2018. Jurnal Pendidikan Islam, 10(2), 1-15.

Yogyakarta : Departemen Pendidikan Nasional Universitas Negeri Yogyakarta

Sari, Asma. (2015). Pengembangan Media Peta Budaya Indonesia pada Mata Pelajaran Ilmu Pengetahuan Sosial bagi Siswa Kelas IV Sekolah Dasar Negeri Rejosari Gunung Kidul. Skripsi. Ilmu Pendidikan. Teknologi Pendidikan. Universitas Negeri Yogyakarta.

Taseman, Iman Rasiman, Arumi Puji Lestari, Atik Anturichana, Hanyfa Maulidiyah, H. H. (2020). IMPLEMENTASI EVALUASI SOAL PEMBELAJARAN IPS THE IMPLEMENTATION OF LEARNING EVALUATION ON SOCIAL STUDIES BASED ON 2013 CURRICULUM AT MI ASSYAFI' IYAH. AULADUNA: Jurnal Pendidikan Dasar Islam, 7(1), 74-80.

Taseman. (2020). Pemanfaatan Media Visual Pada Pembelajaran IPS Di MI Darul Mutaallimin Sidoarjo. BADA'A: Jurnal Ilmiah Pendidikan Dasar, 2(1), 86-97.

Yusuf, A Muri. (2014). Metode Penelitian: Kuantitatif, Kualitatif, dan Penelitian Gabungan. Jakarta: KENCANA

Yuswanti. (2013). Penggunaan Media Gambar Untuk Meningkatkan Hasil Belajar Siswa pada Pembelajaran IPS di Kelas IV SD. PT Lestari Tani Teladan Kabupaten Donggala. Jurnal Kreatif Tadulako Online. 3 (4) : 185-190 
Author (s) :

*I Rasiman (Corresponding Author)

Department of Faculty Education, Institute University of Islamic Al Khoziny Sidoarjo, Indonesia Jl. KH. Khamdani, Siwalan Panji Buduran, Sidoarjo 61252, Indonesia Email: imanrasiman@alkhoziny.ac.id

\section{Taseman}

Department of Faculty Education, Institute University of Islamic Al Khoziny Sidoarjo, Indonesia Jl. KH. Khamdani, Siwalan Panji Buduran, Sidoarjo 61252, Indonesia Email: taseman@alkhoziny.ac.id

\section{Kartikasari}

Department of Faculty Teacher and Education, Islamic State University of Sunan Ampel, Surabaya, Indonesia Jl. Ahmad Yani 117, Surabaya, East Java, 60237, Indonesia Email: kartikasari.intan230@gmail.com

\section{W Laili}

Department of Faculty Teacher and Education, Islamic State University of Sunan Ampel, Surabaya, Indonesia Jl. Ahmad Yani 117, Surabaya, East Java, 60237, Indonesia Email: mifrohwafi07@gmail.com

\section{Muzdalifa}

Department of Faculty Teacher and Education, Islamic State University of Sunan Ampel, Surabaya, Indonesia Jl. Ahmad Yani 117, Surabaya, East Java, 60237, Indonesia Email: muzdachsnyh11@gmail.com

\section{S Maryam}

Department of Faculty Teacher and Education, Islamic State University of Sunan Ampel, Surabaya, Indonesia Jl. Ahmad Yani 117, Surabaya, East Java, 60237, Indonesia Email: mayacyantik10@gmail.com 